\title{
Numerical simulation and optimization of shell mould casting process for leaf spring bracket
}

\author{
Ji-guang Liu', Lei Yang', *Xiao-gang Fang', Bin Li', You-wen Yang', Li-zhi Fang', Zheng-bing Hu² \\ 1. School of Materials Science and Engineering, Hefei University of Technology, Hefei 230009, China \\ 2. Hefei South Automobile Component Co. Ltd., Hefei 231200, China
}

\begin{abstract}
Although the shell mould casting process has a wide range of application in many fields, the prediction of casting defects is still a problem. In the present work, a typical leaf spring bracket casting of ZG310570 was fabricated by shell mold casting. The finite element model and ProCAST software were utilized for simulating the filling and solidification processes of the casting; and the formation mechanism of the gas pore, and shrinkage porosity defects were analyzed. The results indicate that the gas pore and shrinkage porosity defects are formed due to air entrapment, insufficient feeding and non-sequential solidification. Subsequently, through changing the position of risers, adding a connecting channel between the risers, and setting blind risers at the U-shaped brackets, an optimized gating and feeding system was established to improve the quality of the casting. After optimization, the gas pore and shrinkage porosity defects of the leaf spring bracket casting are effectively eliminated. The experiment results with the optimized casting process are in good agreement with the numerical simulation, which verifies the validity of the finite element model in the shell mould casting.
\end{abstract}

Key words: shell mould casting; numerical simulation; leaf spring bracket; process optimization

CLC numbers: TG142/TP391.9 Document code: A Article ID: 1672-6421(2020 01-035-07

$\mathrm{T}$

he castings produced by the shell mould casting

process have a number of attractive advantages, including a clear outline, small processing allowance and high dimensional accuracy ${ }^{[1]}$. It has broad application prospects in many fields, such as automotive parts, military products and hardware tools. In recent years, more and more attentions have been paid to the shell mould casting process of complex parts. Due to the inefficient shell exhaust and the non-uniform heat transfer on the shell surface, gas pore, cavity, and shrinkage porosity defects are prone to occur in the solidification process of the shell mould casting, especially for complex castings with uneven thickness ${ }^{[2-3]}$. These defects seriously deteriorate the mechanical properties of the castings ${ }^{[4-5]}$.

Numerical simulation method is normally employed to analyze the pouring and solidification processes. It can predict the gas pore, cavity and shrinkage porosity defects and their locations ${ }^{[6]}$. At present, most investigations

Male, born in 1989, Ph. D. His research interests mainly focus on the development of new light alloy materials, liquid metal forming technology, and numerical simulation of the casting process. To date, he has published more than 20 technical papers.

E-mail: fangxg@hfut.edu.cn based on the numerical simulation of the casting process focus on gravity casting and low pressure casting, few of them focus on the shell mould casting process ${ }^{[7]}$. Zuo Shanchao, et al. ${ }^{[8]}$ used View Cast software to simulate the shell mould casting of a wear resistant plate with simple structure. They optimized the casting process by increasing the diameter and height of the sprue, and finally eliminated the casting defects of shrinkage cavity and porosity on the top of the casting. Zhang Jun-qiang, et al. ${ }^{[9]}$ used View Cast software to simulate the shell mould casting process of the camshaft with a relatively complex structure. They optimized the casting process by increasing the riser size and adding chills to the thick part, significantly eliminating the shrinkage cavity and shrinkage porosity defects. For the casting with more complex structure, the analysis of the gas distribution in the pouring process can be added to the simulation, which makes the results more comprehensive.

As an important supporting part in the automobile suspension system, the leaf spring bracket plays the role of fixing the leaf spring. Figure 1 is a three-dimensional model of a leaf spring bracket with complex structure, which is mainly composed of the foot column, web plate, reinforcing rib and the U-shaped bracket. In this study, the finite element software ProCAST is used to analyze the filling and solidification processes, gas distribution, and defect formation mechanism of the 
leaf spring bracket in the shell mould casting process. Based on this analysis, the optimization scheme of the process was put forward, and then the casting experiment was carried out with the optimal process. The study can provide a theoretical guidance for the production of the shell mould casting process.

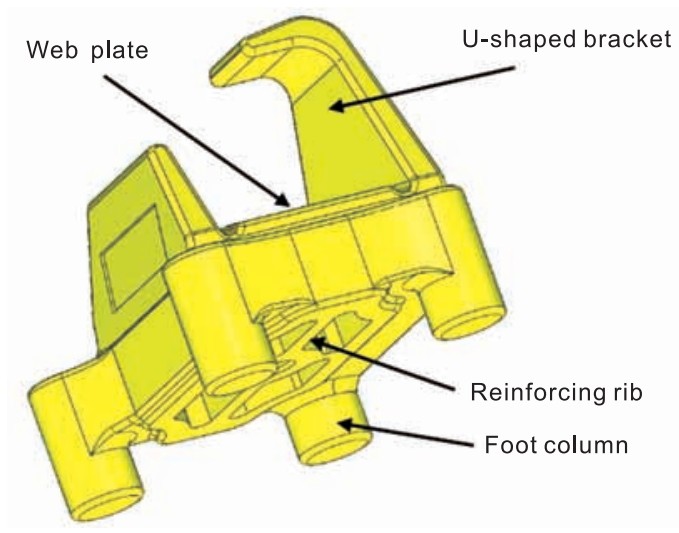

Fig. 1: Three-dimensional model of leaf spring bracket

\section{Numerical simulation procedure}

The material of the casting is ZG310-570, which has a high melting point, a high pouring temperature and a high thermal effect of molten steel on sand moulds ${ }^{[10-12]}$. The chemical composition of ZG 310-570 is shown in Table 1. Figure 2 shows the three-dimensional model of the leaf spring bracket casting together with the gating and feeding system which are built by SolidWorks software. The outline size of the leaf spring bracket casting is $200 \mathrm{~mm} \times 170.8 \mathrm{~mm} \times 184 \mathrm{~mm}$. The upper part has a U-shaped bracket, and the bottom has a web plate, of which the thinnest part is $10 \mathrm{~mm}$, and the thickest part is $54 \mathrm{~mm}$. The difference in thickness of the casting is great and the structure is complex. A closed gating and feeding system with one mould and two pieces is initially designed. The two castings are connected by the cushion platforms at the foot column of the castings. Two tapered risers with the same size are set along the length direction of the casting, and one of them is chosen as the gate. The height of the risers is $140 \mathrm{~mm}$, the volume is $600,000 \mathrm{~mm}^{3}$, and the overall mass is about $33 \mathrm{~kg}$.

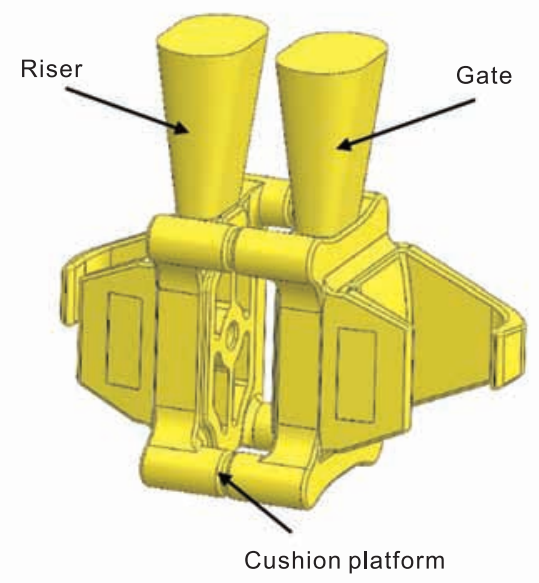

Fig. 2: Gating and feeding system of the casting

Table 1: Nominal chemical compositions of ZG 310-570 (wt. \%)

\begin{tabular}{|c|c|c|c|c|c|c|c|c|c|}
\hline C & Si & Mn & $\mathbf{S}$ & $\mathbf{P}$ & $\mathrm{Ni}$ & $\mathrm{Cr}$ & Mo & V & $\mathrm{Cu}$ \\
\hline $0.42-0.52$ & $0.4-0.5$ & $0.7-1.0$ & $\leqslant 0.04$ & $\leqslant 0.04$ & $\leqslant 0.3$ & $\leqslant 0.3$ & $\leqslant 0.2$ & $\leqslant 0.05$ & $\leqslant 0.3$ \\
\hline
\end{tabular}

As shown in Fig. 3, the casting is obtained after cleaning, cutting and grinding. There are a number of shrinkage porosities in the middle of the casting web plate and the end of the U-shaped bracket. Besides, some gas pores are found in the foot columns and at the junction of the riser and casting.

ProCAST software is utilized for simulating the filling and solidification process. In the MeshCAST module, the mesh size is $5 \mathrm{~mm}$, and there are 400,947 cells in total. In ProCAST module, the shell mould casting mode is selected and the corresponding parameters are selected as shown in Table 2. The surface heat transfer conditions of the shell mold and the two risers are set as air cooling.

\section{Results and discussion}

\subsection{Numerical simulation of original casting process}

Figures 4 and 5, respectively, show the numerical simulation results of the filling process and the air distribution in the original process scheme. The metal flow is relatively fast when the metal liquid fills into the mold cavity. The turbulence and
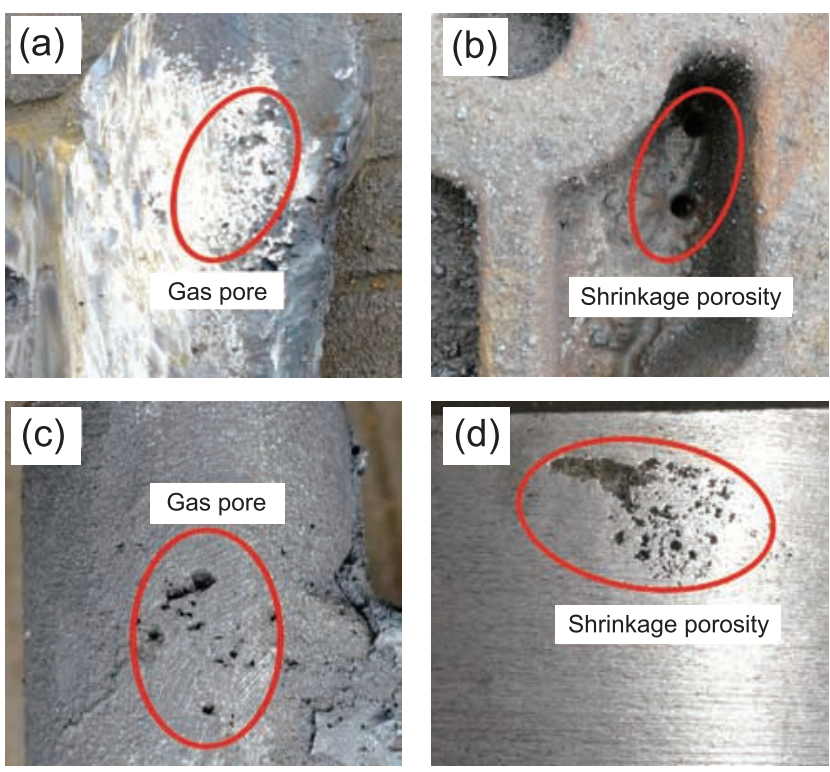

Fig. 3: Defects in different parts of casting: (a) gas pores at the junction of the riser and casting; (b) shrinkage porosity in the middle of casting web plate; (c) gas pores at the foot columns; (d) shrinkage porosity in the end of the U-shaped bracket 


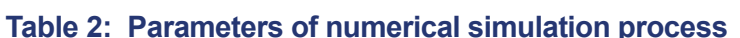

\begin{tabular}{|c|c|}
\hline$\square \square[\square \square \square \square]$ & $\square \square \square \square$ \\
\hline Pouring temperature $\left({ }^{\circ} \mathrm{C}\right)$ & 1,550 \\
\hline Pouring time (s) & 5 \\
\hline Shell mould material & Resin bonded sand \\
\hline Shell mould thickness (mm) & 10 \\
\hline Shell mould temperature $\left({ }^{\circ} \mathrm{C}\right)$ & 20 \\
\hline $\begin{array}{l}\text { Heat transfer coefficient between the } \\
\text { shell mold and casting }\left(\mathrm{W} /\left(\mathrm{m}^{2} \cdot \mathrm{K}\right)\right.\end{array}$ & 500 \\
\hline
\end{tabular}

the spattering occur at the foot columns of the bottom of the mold cavity, which results in the air entrapment. As shown in Fig. 5(a), there is an obvious air entrapment at the foot columns, leading to the formation of the gas pores. At $1.01 \mathrm{~s}$ [Fig. 4(a)], the liquid metal fills the pairs of foot columns at the bottom, and the liquid metal flow is turbulent. At the filling stage from $2.03 \mathrm{~s}$ to $3.02 \mathrm{~s}$, the filling process is stable and the liquid metal level rises to $2 / 3$ of the U-shaped bracket. When the filling time reaches $4.04 \mathrm{~s}$, the liquid metal fills the upper area of the foot columns. At this time, the rapid reduction of the cross-sectional area of the cavity accelerates the filling speed, which makes it difficult for some gas in the cavity to release in time, and it is finally trapped in this region, as shown in Fig. 5(c).

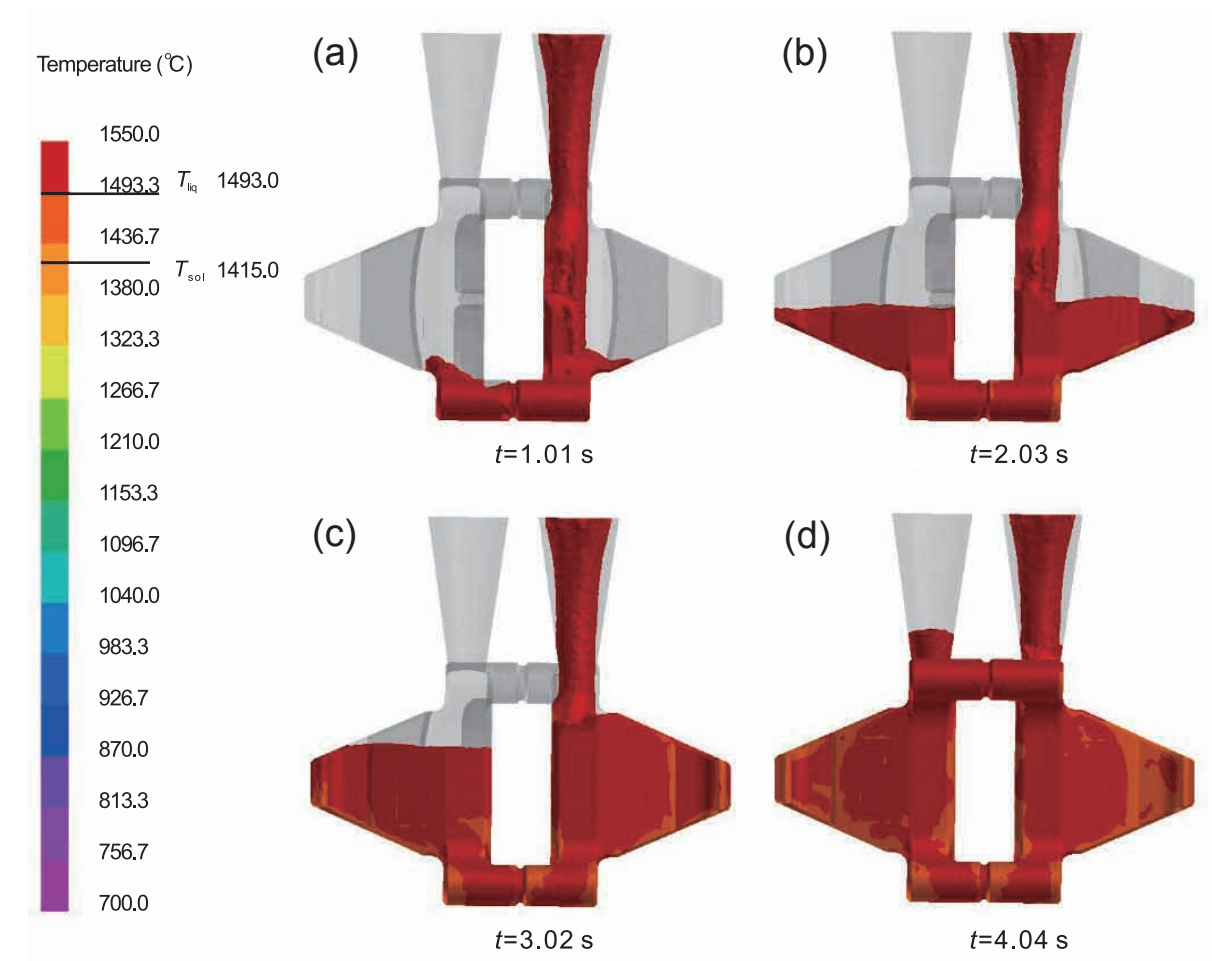

Fig. 4: Numerical simulation results of filling process

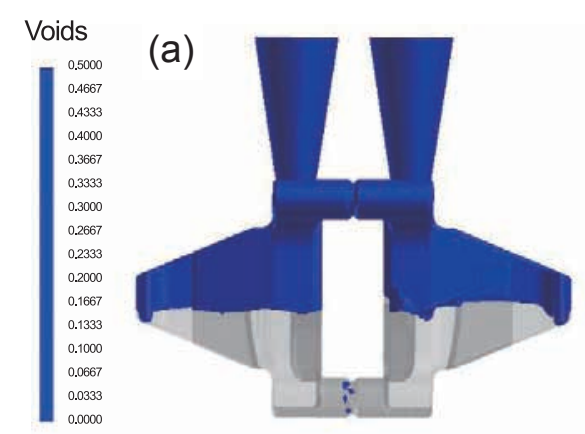

$t=2.03 \mathrm{~s}$

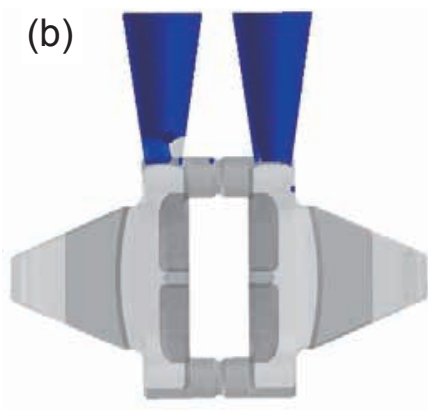

$t=4.04 \mathrm{~s}$

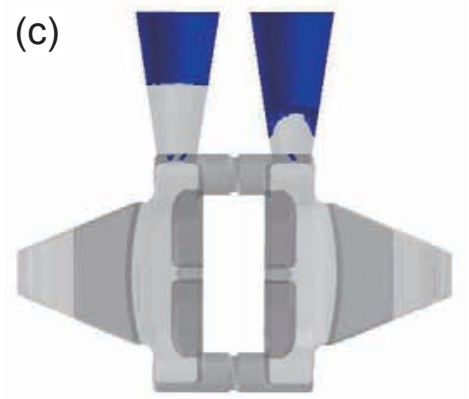

$t=4.3 \mathrm{~s}$

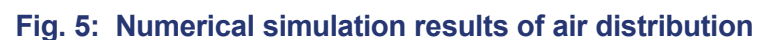

The solidification process of the casting is shown in Fig. 6. It takes about $22 \mathrm{~min}$ to complete the solidification process. With the decrease of the temperature, the casting begins to solidify and shrink from the thin-walled U-shaped bracket area at 78 s. At this point in time, the hot spot area lies in the smaller cross section of the U-shaped bracket, leading to the lagging 


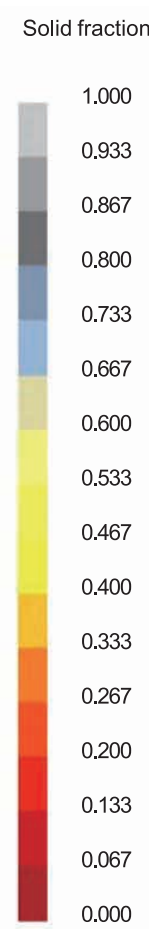

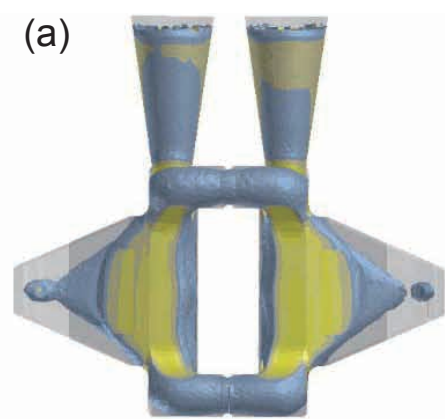

$t=78 \mathrm{~s}$

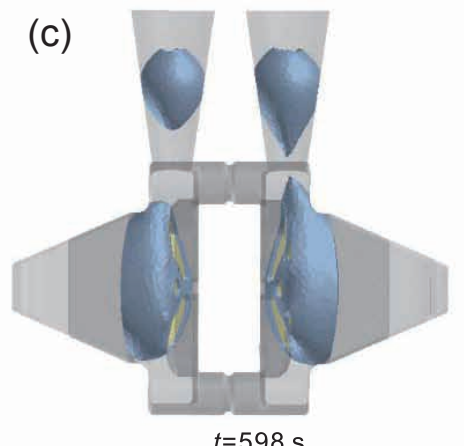

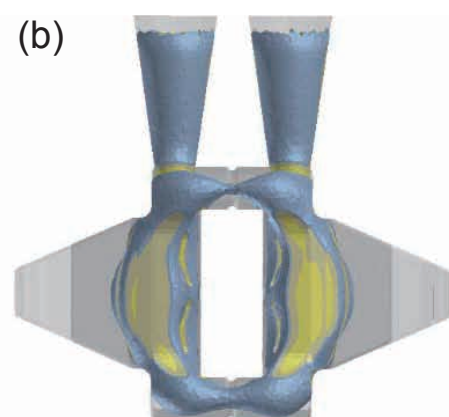

$t=138 \mathrm{~s}$

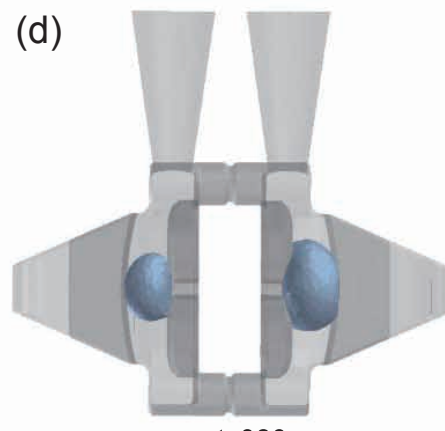

$t=828 \mathrm{~s}$

Fig. 6: Numerical simulation results of solidification process

solidification and the formation of obvious isolated molten pools. At the solidification stages from $138 \mathrm{~s}$ to $598 \mathrm{~s}$, the thick and large part of the casting web plate begins to cool and solidify. Meanwhile, the feeding channel at the junction of the riser and the casting is cut off, so it is impossible to effectively feed the shrinkage inside the casting. During the solidification process, large isolated molten pools are formed in the thick part of the casting web plate at $828 \mathrm{~s}$. Because the isolated molten pools cannot obtain the feeding of molten metal, the serious shrinkage porosity defects are formed in these parts during the solidification shrinkage stage.

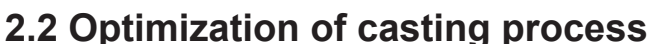

From the above simulation results, the calculated volume of shrinkage porosity (the porosity above $1.8 \%$ ) is $19,400 \mathrm{~mm}^{3}$, which is consistent with the defect type and location in the actual operating condition of the castings. It is proved that the parameters set by the software in the numerical simulation are reasonable and can provide accurate boundary conditions for the subsequent process optimization.

There are a lot of gas pore, cavity and shrinkage porosity defects in the leaf spring bracket casting, which seriously affect the casting quality. In addition, the material of the casting, ZG310-570, has a fast cooling rate, poor fluidity, a high solidification shrinkage and easy oxidation during the filling and solidification processes. In order to improve the comprehensive quality of the casting, optimization of the pouring scheme is carried out. The gating and feeding system of the optimization scheme is shown in Fig. 7. In order to ensure the molten steel is injected into the cavity smoothly, and to avoid the collision or turbulence of molten steel, the flow distance of molten steel in the cavity should be shortened

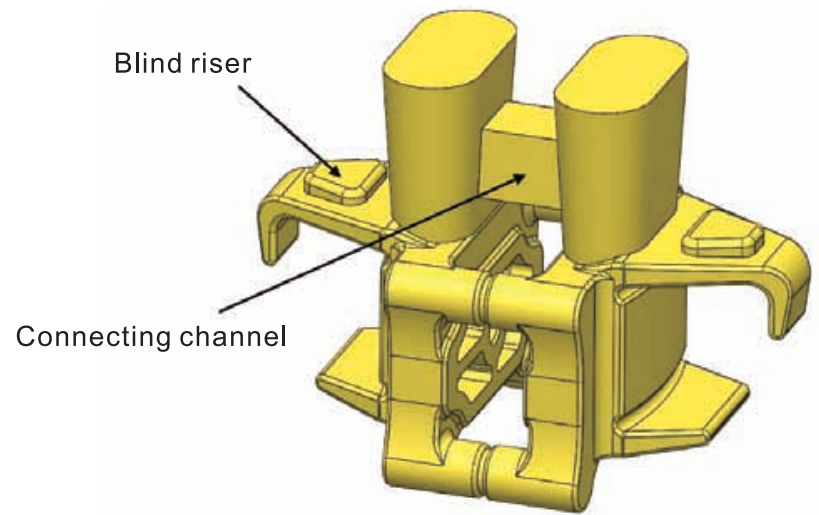

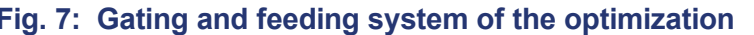 $\square \square \square \square \square \square$}

as much as possible. In the optimization design, the riser is changed from along the length direction to along the width direction of the casting to reduce the drop from the gate to the bottom of the cavity, which can slow the flow rate of the liquid metal and reduce splashing and turbulence.

According to the principle of metal solidification, the local overheating and isolated molten pools easily lead to the formation of the shrinkage defects ${ }^{[13-14]}$. In the original scheme, on the one hand, the riser is tapered, and the joint between riser and casting is repeatedly scoured by molten metal during the filling process, which results in the local overheating. The cooling rate of this part is slowed down and the solidification time is prolonged, which makes it easy to cause shrinkage porosity defects. On the other hand, the premature solidification of the alloy at the lower part of riser forms a huge dendrite area, which cut off the feeding channel. After 598 s [Fig. 6 (c)], the 
subsequent molten metal cannot feed the casting inside through the feeding channel. The solidification shrinkage caused by the cooling of the liquidus to the solidus in the isolated molten pools inside the casting cannot be fed, resulting in shrinkage porosity defects. In order to improve this situation, the shape of the riser is changed from cone to waist to increase the crosssectional area of the junction between the riser and casting. The riser volume can be calculated by the $Q$-parameter method ${ }^{[15]}$ :

$$
Q=\frac{V_{\mathrm{C}}}{M_{\mathrm{C}}{ }^{3}}
$$

where $V_{\mathrm{C}}$ is the volume of the feeding part $\left(\mathrm{mm}^{3}\right) ; M_{\mathrm{C}}$ is the modulus of the feeding part. For the riser design of steel castings, the following function is applied:

$$
\frac{V_{\mathrm{C}}}{V_{\mathrm{R}}}=\frac{200.0}{Q}+0.15
$$

where $V_{\mathrm{R}}$ is the volume of riser $\left(\mathrm{mm}^{3}\right)$. Finally, the riser volume $V_{\mathrm{R}}$ is calculated to be $53,470 \mathrm{~mm}^{3}$.

The volume shrinkage of the leaf spring bracket casting is great, which makes it easy to produce the shrinkage cavity defects. From the analysis of the original gating and feeding system, the shrinkage defects mainly occur in the U-shaped bracket and the web plate of the casting, which should be optimized according to the principle of sequential solidification. In the optimization scheme, a blind riser is set at the thinner section of the U-shaped bracket as a padding to make the part solidify sequentially in the direction of the riser during the solidification. The volume of the blind riser is $23,530 \mathrm{~mm}^{3}$, which is calculated by Eqs. (1) and (2). Through several times of numerical simulation tests, a connecting channel with a volume of $157,863 \mathrm{~mm}^{3}$ is set between the two open risers. The optimized gating and feeding system can not only increase the feeding amount without increasing the height of riser, but also make the risers stay at a higher temperature for a long time. Therefore, it slows down the solidification speed at the risers, which results in the sequential solidification. The sequential solidification can give full play to the feeding effect of the risers, preventing the formation of the shrinkage cavity and shrinkage porosity.

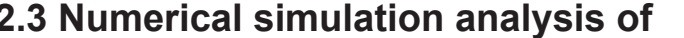

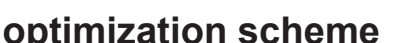

After optimizing the gating and feeding system, the filling and solidification processes of leaf spring bracket casting were analyzed under the condition of the pouring temperature of $1,550{ }^{\circ} \mathrm{C}$ and the filling time of $5 \mathrm{~s}$. Figure 8 shows the flow velocity at the bottom foot columns of the cavity. Comparing the two schemes in Fig. 8(a) and Fig. 8(b), the maximum flow velocity range of the original scheme and the optimized scheme is $0.704-1.127 \mathrm{~m} / \mathrm{s}$ and $0.423-0.704 \mathrm{~m} / \mathrm{s}$, respectively. The filling speed of liquid metal at the foot column in the optimized scheme is slower than that in the original scheme, so the optimization scheme reduces the possibility of air entrapment. In addition, the effective section area of the liquid metal surface at the bottom of the cavity is increased from $13,585.48 \mathrm{~mm}^{2}$ to $23,055.22 \mathrm{~mm}^{2}$. Enlargement of the effective section makes it easier for the gas involved in the liquid metal to be discharged. Figure 9 shows the filling process of the optimization scheme. The figure shows the temperature distributions of the casting after the metal liquid filling in the mold cavity at $1.09 \mathrm{~s}, 2.03 \mathrm{~s}$, $3.25 \mathrm{~s}$ and $3.81 \mathrm{~s}$, respectively. At $1.09 \mathrm{~s}$, the liquid metal fills the foot column at the bottom of the casting, the flow rate of the liquid front is small, the liquid surface is relatively stable, and there is no obvious turbulence and splash. At $3.81 \mathrm{~s}$, the liquid metal fills the cavity of the whole castings, and the liquid steel flow is stable during the whole filling process without air entrapment.

Figure 10 shows the solidification process of the optimization scheme. This figure shows the distribution of liquid metal in the cavity at $106 \mathrm{~s}, 1106 \mathrm{~s}$ and 1,235 s, respectively. At $106 \mathrm{~s}$ [Fig. 10(a)], the blind riser at the U-bracket of the casting begins to solidify. It can be seen that the influence of the hot spot can be effectively eliminated, which promotes the sequential solidification of the U-shaped bracket, and eliminates the tendency of the isolated molten pool by setting the blind riser. In the original scheme, the feeding channel between the final solidification area of the casting web plate and the riser was cut off, which results in serious shrinkage defects. After optimization, the connecting channel is set between the two risers to increase the amount of the feeding. At 1,106 s, the
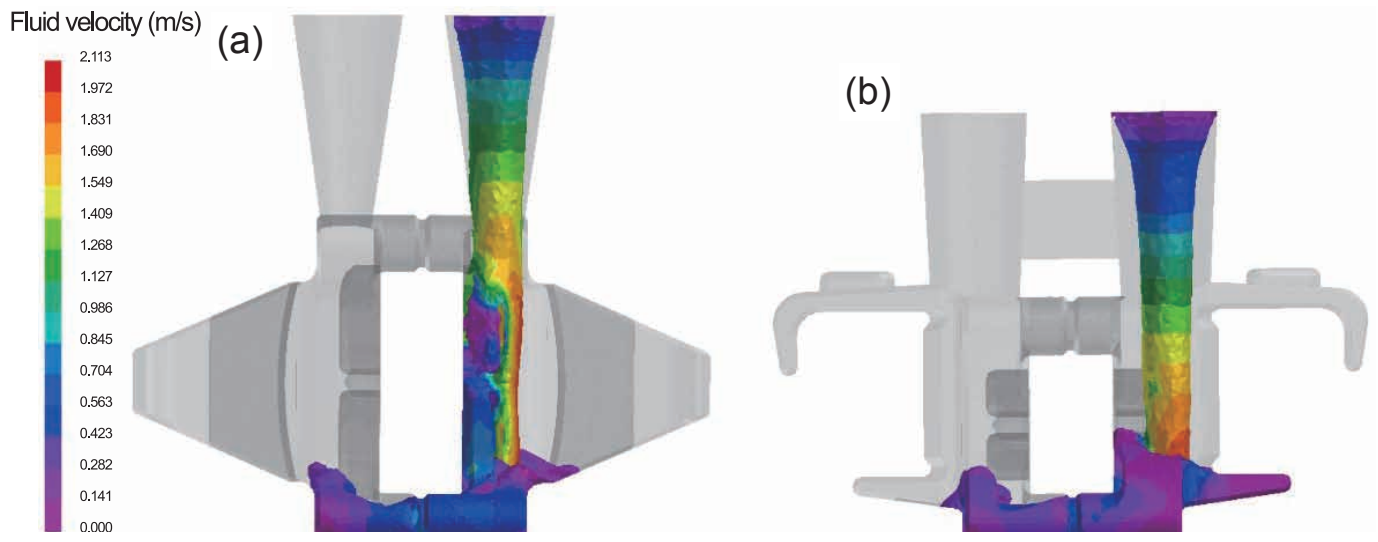

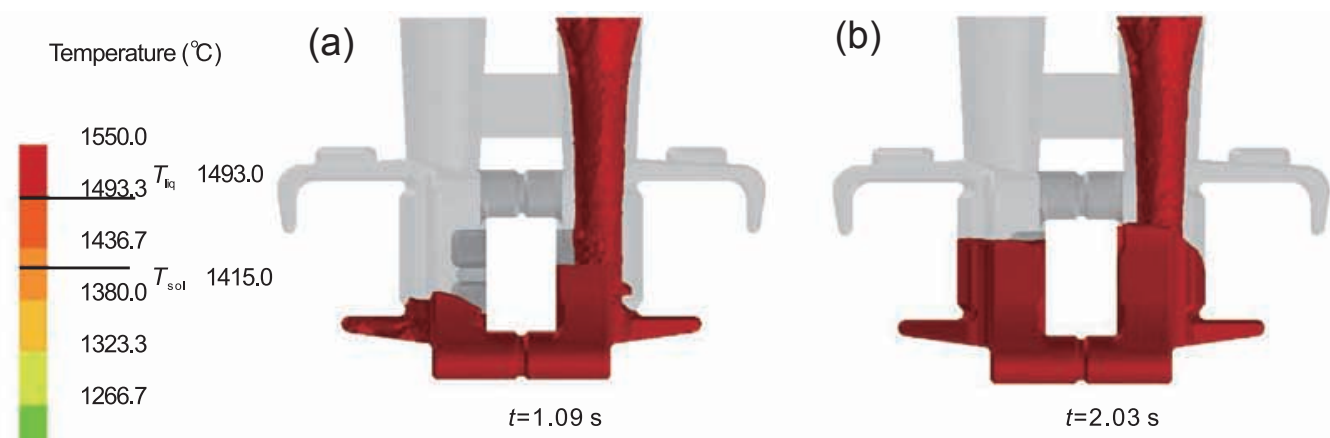

1210.0

1153.3

1096.7

1040.0

983.3

926.7

870.0

813.3

756.7

700.0

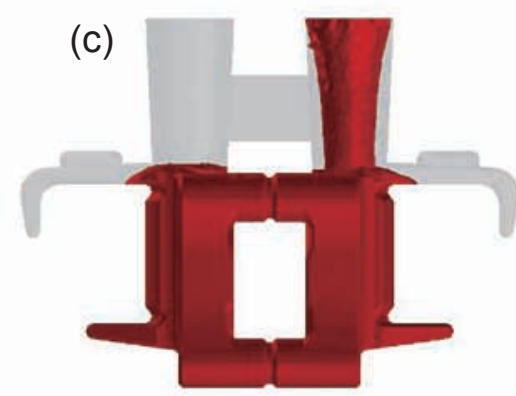

$t=3.25 \mathrm{~s}$

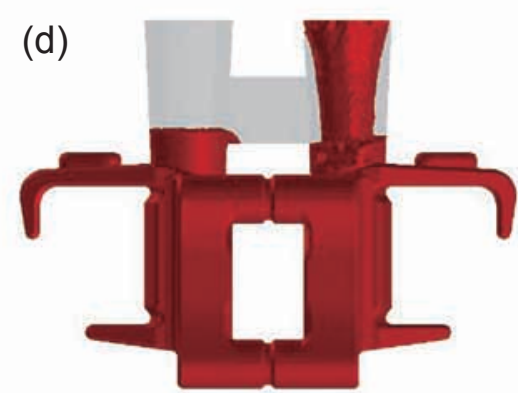

$t=3.81 \mathrm{~s}$

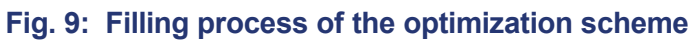

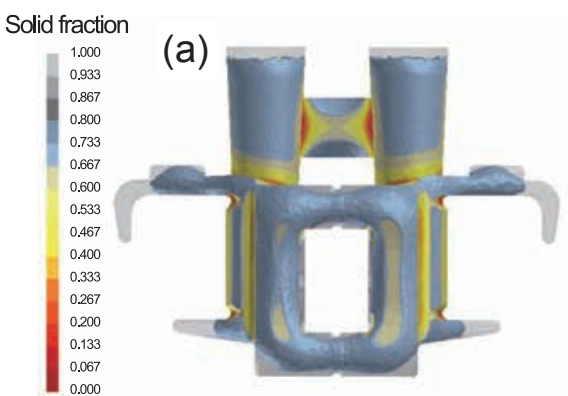

$t=106 \mathrm{~s}$

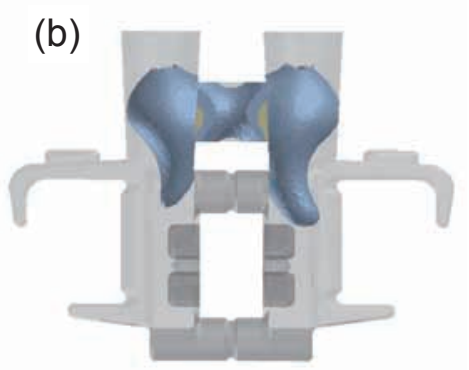

$t=1106 \mathrm{~s}$

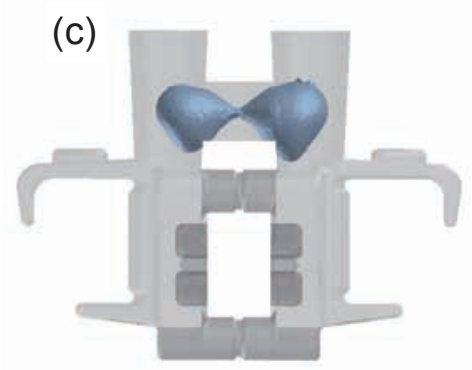

$t=1235 \mathrm{~s}$

Fig. 10: Solidification process of optimization scheme

feeding channel between the risers and castings is still open, and the solidification shrinkage at the web plate of castings still can be fed. At 1,235 s, except for the gating and feeding system, the temperature in the castings drop below the solidus. At this part in time, under the action of the temperature difference from outside to inside, the casting finally solidifies layer by layer, and there is no obvious isolated molten pool during this process.
After optimization, the shrinkage porosity volume of castings decreases from $19.4 \mathrm{~mm}^{3}$ to $0.1 \mathrm{~mm}^{3}$. Figure 11 shows the shrinkage porosity defects of castings under different technological conditions. It can be clearly observed that the shrinkage porosity defects at the foot columns, the thick parts of the U-shaped bracket and the web plate of the castings are effectively eliminated, except for a few remained in the non-

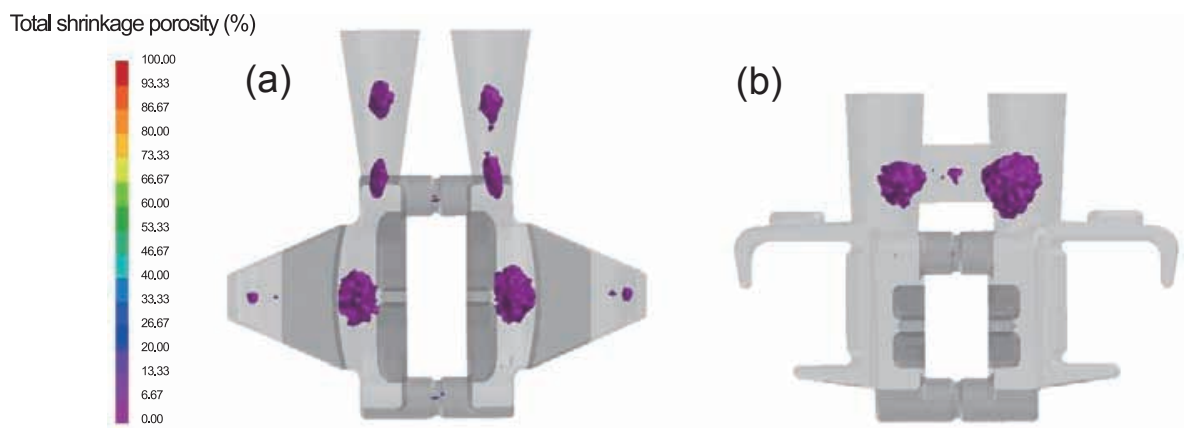


critical parts.

The castings are trial-produced according to the optimized scheme. The shell mould casting process is carried out under the pouring temperature of $1550{ }^{\circ} \mathrm{C}$ and the pouring time of $5 \mathrm{~s}$. The casting obtained is shown in Fig. 12. The distribution of defects is basically consistent with the numerical simulation results. By X-ray non-destructive testing, the castings show excellent comprehensive quality, compact internal structure, no obvious shrinkage porosity and cavity defects. The reliability of the optimization scheme is proved.

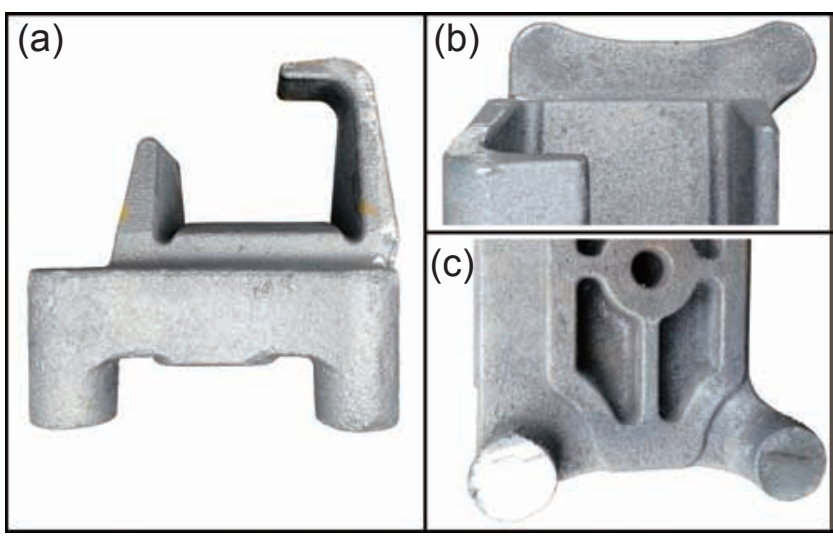

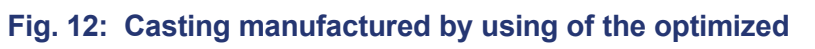

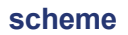

\section{Conclusions}

Through numerical simulation, the shell mould casting process of the leaf spring bracket with complex structure is deeply analyzed. The following conclusions can be made:

(1) The defects at the junction of the riser and casting, the middle of the casting web plate, the end of U-shaped bracket, and the foot column are mainly caused by air entrapment, insufficient feeding and non-sequential solidification.

(2) The gating and feeding system is optimized by changing the riser position of the leaf spring bracket, setting up the connecting channel between the risers, and adding a blind riser at the U-shaped bracket. After the optimization, the shrinkage volume of castings decreases from $19.4 \mathrm{~mm}^{3}$ to $0.1 \mathrm{~mm}^{3}$, and the porosity defects of the casting are noticeably eliminated.

(3) The experimental results of the optimized scheme show good agreement with the numerical simulation, which verifies the validity of the finite element model in the shell mould casting.

\section{Acknowledgements}

This study is financially supported by the Major Science and Technology Projects in Anhui Province (No. 18030901097), the Natural Science Foundation of Anhui Province (No.1908085QE197), and the Fundamental Research Funds for the Central Universities (JZ2018HGBZ0133, JZ2019HGTA0043).

\section{References}

[1] Le Serve F L. Shell moulding maintains status as leading precision sand casting technique. Foundry Trade Journal,1981 (11): 707-715.

[2] Shepel S V, Paolucci S. Numerical simulation of filling and solidification of permanent mold castings. Applied Thermal Engineering, 2002, 22 (2): 229-248.

[3] Murakami Y. Effects of small defects and nonmetallic inclusions on the fatigue strength of metals. Key Engineering Materials, 1991, 51-52: 37-42.

[4] Liu W, Zhai W H, Zhao J F. Influence of shrinkage porosity on fatigue performance of iron castings and life estimation method. China Foundry, 2016, 13 (1): 47-53.

[5] Nadot $Y$, Mendez J, Ranganathan N. Influence of casting defects on the fatigue limit of nodular cast iron. International Journal of Fatigue, 2004, 26(3): 311-319.

[6] Sulaiman S, Hamouda A M S, Abedin S, et al. Simulation of metal filling progress during the casting process. Journal of Materials Processing Technology, 2000, 100 (1-3): 224-229.

[7] Han D D, Wang C J, Chang J, et al. Numerical Simulation of Filling and Solidification in Sand Casting by Procast. Advanced Materials Research, 2013, 791-793: 550-553.

[8] Zuo S C, Li C Y, Mi G F, et al. Design and optimization of shell mold casting process for cast-iron wear-resisting plate. Hot Working Technology, 2016 (7): 74-83. (In Chinese)

[9] Zhang J Q, Mi G F, Wang Y C, et al. Shell casting process optimization of a chilled cast iron camshaft. Hot Working Technology, 2016(17): 78-81. (In Chinese)

[10] Beenesh M, Yadav N P. Prediction of solidification behaviour of alloy steel ingot casting. Materials Today: Proceedings, 2018: $20380-20390$.

[11] Lan P, Zhang J Q. Numerical analysis of macrosegregation and shrinkage porosity in large steel ingot. Ironmaking \& Steelmaking, 2014, 41 (8):598-606.

[12] Radovic Z, Lalovic M. Numerical simulation of steel ingot solidification process. Journal of Materials Processing Technology, 2005, 160 (2): 156-159.

[13] Liu Q K. Basic Principles of Material Forming. China Machine Press, 2010. (In Chinese)

[14] Li R D, Mi G F. Foundry Technology. China Machine Press, 2013. (In Chinese)

[15] Foundry Institution of Chinese Mechanical Engineering Society. Foundry Manual: Volume 5, Foundry Technology. China Machine Press, 2011. (In Chinese) 